\title{
Innovation Research and Practice Teaching System of Modern Engineering Graphics
}

\author{
Yue Fang, Jian-ying Liu \\ College of Mechanical Engineering, Henan Engineering College, Zhengzhou, Henan, 450007, China \\ fangyue0904@126.com
}

\begin{abstract}
Establishing teaching system with the characteristics of era of modern engineering graphics is used to the development of science and technology, cultivate student innovative ability. At the same time, this system makes course conducive to the cultivation of student comprehensive quality. Analyzing and studying the trend of the development of modern engineering graphics. It makes remarkable achievements in the connotation and extension of engineering graphics class, course orientation, teaching system and teaching content of planning and integration, teaching means, examination mode and the teaching quality evaluation system of innovation research being carried on the bold reform practice.

Index Terms - engineering graphics ; teaching system innovation ; teaching quality
\end{abstract}

\section{Introduction}

Seeking innovation in the inheritance and innovation for development, is the common characteristic and law of construction of the curriculum reform in colleges and universities. With the development of science and technology, especially the introduction of computer technology, not only teaching system and teaching content but also teaching methods and means have made great changes in modern engineering graphics. Establishing teaching system with the characteristics of era of modern engineering graphics is used to the development of science and technology, cultivate students' innovative ability. At the same time, this system makes course conducive to the cultivation of student comprehensive quality. Analysising and studying the trend of the development of "modern engineering graphics" ,which makes remarkable achievements in the connotation and extension of engineering graphics class, course orientation, teaching system and teaching content of planning and integration, teaching means, examination mode and the teaching quality evaluation system of innovation research being carried on the bold reform practice. Modern innovation research and practice of engineering graphics teaching system is based on the core of improving the teaching quality, build a modular, integrated, creative new teaching system that makes configuration design as the main line. Clear the new concept of innovative education and practice. New teaching system breaks through the confine of "engineering drawing" course to integrate the engineering design concept to the teaching of engineering graphics, and make course conducive to the cultivation of the student comprehensive quality in its overlapping and era characteristics [1-6].

\section{The Scheme of the New Teaching System for Modern Engineering Graphics}

Correctly understanding the teaching goal, task and development trend of engineering graphics, and is in accordance with the thick foundation, wide scope, strong ability and high quality talent training requirements, with fusion on the basis of comprehensive design ability training as the main line three class, paying equal attention to "three laws, three simultaneously, innovative thinking and the design drawing ability training as the core, by means of modern education technology, the ability to build outstanding configuration, engineering consciousness and engineering quality training of new courses teaching system[7].

Modern engineering graphics teaching new system consists of descriptive geometry and engineering drawing, computer graphics, CAD, computer graphics, creative configuration design, simulation, training modules, such as teaching fully embody the" modern engineering graphics new ideas. Its characteristics are:

1) Three classes, namely descriptive geometry, engineering drawing, computer drawing ,three classes in content is suigeneris and permeate organically integrate with each other together, meanwhile, make the traditional engineering graphics of teaching universality, in its overlapping and era characteristics, forming modern engineering graphics new system.

2) The three pay equal attention to, that is, in the teaching, to form analysis, line surface analysis, configuration analysis are as a student's drawing, map reading, doing the basic methods of training creative configuration design, strengthening the students' ability of creative configurations.

3) Three figure developing simultaneously, namely the ruler gauge drawing, computer graphics, freehand drawing three drawing skills when students express design flexible use, lead the student to have accurate and fast ability to communicate design ideas and concepts. Consequently, complete the teaching aim of engineering graphics from a mere illustration, graphic to training creative configuration ability.

\section{The Reform of the Teaching Methods}

Optimize the structure of classroom then two-way develop student's knowledge and ability. Change the teachercentered teaching of the single transmission of knowledge, change force-feeding teaching for heuristic teaching, teaching students to learn to teach students to learn. The expansion of a 
single classroom teaching into classroom teaching, student self-study, discussion, practice, and other forms, form an open teaching mode. Such as creative start of configuration design, namely, heuristic, interactive, discussion-based teaching method, expand students' thinking, guide the student to carry on the interactive discussion, let the students actively involved in the teaching. Creativity in the process of configuration design, promote students to think independently, and hands-on exercises self-study ability, starting from the existing knowledge, inspire students' brains to discover problems, and then to analyze problems, finally solve the problem.

\section{Modern Education Technology becomes One of the Important Teaching Means for Modern Engineering Graphics}

\section{A. The CAI Multimedia Courseware}

Modern education technology is the important means for the implementation of the new teaching system and the important embodiment of the reform of teaching methods, teaching means. As a result of engineering graphics class space and abstractness, in the teaching process to form a complete set of charts, the model, which use the image of visual teaching methods.2005 years later, for all kinds of problems in teaching, we developed the advanced interactive function of CAI courseware for modern engineering graphics multimedia teaching system, the system can real-time stereo projection, dynamic demonstration and simulation process. It creates a multi-level and more visual three-dimensional learning space, both teaching and learning by using video effects interact directly, to make the teaching more intuitive, teaching content easier to understand. The system pays attention to cultivate student space thinking ability and space imagination ability, good openness, teachers can use this as a platform. Making the personalized electronic lesson plans teaching has its own characteristics. To help students improve their study interest, strengthen students' understanding of knowledge and memory, and give full play to the student subjective dynamic role, greatly improve the teaching efficiency and teaching quality, achieve good teaching effect[8].

\section{B. The Network Classroom}

Through the establishment of network classroom for modern engineering graphics break the limit of time, space, remote teaching, give full play to the excellent teacher much experience of teaching, improve students' learning initiative and enthusiasm, to realize individualized teaching, so as to improve teaching effect, ensure the quality of teaching. Modern engineering graphics goal is to make full use of existing network teaching system and the future of network resources, curriculum resources, to provide modern engineering graphics of a three-dimensional, interactive teaching environment to facilitate student learning. For all sorts of problems in teaching, established in 2009 approved field after we have independent research and development of excellent courses with advanced interactive function of network classroom, modern engineering graphics network classroom, as approved in 2010 to establish provincial excellent courses, 2012 successful upgraded to the provincial high-quality goods resource sharing, the system is becoming more and more perfect. At present the main function and structure is as follows:

(1)releasing the syllabus and the teaching plan.

(2) the design of electronic classroom, the students through online identity authentication can realize online learning and browse the content of engineering drawing course.

(3) establishing a problem to solve module, so that the students can solve the problems in the operation.

(4) establishing a "classroom" so that the students can answer questions in establishing online discussions .

(5) establishing a model base, to help the student to carry on the spatial analysis and design.

\section{The Practice of Teaching Reform}

Combined with the educational reform ideas, to reform and reorganization of the practice teaching link into the teaching of engineering graphics system reform plan. New computer three-dimensional configuration, creative design, parts of configuration design, restored parts disassembling, surveying and mapping practice teaching link, the students through the computer structure $3 \mathrm{~d}$ model and configuration design creativity, tear open outfit, parts of surveying and mapping, such as practice teaching, engineering consciousness, foster and improve the ability to get, makes every effort to make the students after graduation can do their work in the engineering technology of soon[9].

Guide students to make full use of campus laboratory in good condition, in the use of AutoCAD 3D function, DIY intersecting line structure, interfingering lines, assembly encountered in the practice of physical model, reappearance of descriptive geometry and drawing in space. To make the students in class and extracurricular practice teaching link, can merge the classroom knowledge in exercise, learn to refer to engineering data and graphic presentation skills and drawing skills.

\section{The Reform of Evaluation Means}

Axplore a variety of test methods and ways. So we get a single question paper examination for multivariate evaluation system, form a multi-level and pluralistic evaluation model, the assessment of knowledge and practical ability of configurations, view, expression ability, creative configuration design of innovation consciousness, drawing speed (i.e., the basic skills of drawing) and so on comprehensive evaluation. Such as adding the computer drawing of the actual operation skills test, engineering drawings, parts, dismantling, surveying and mapping of the defense system. Change "a roll of finalized" approach, using the question paper grades, job performance at ordinary times, large creative configuration, computer graphics computer exam grade, comprehensive evaluation of students course grade. To promote the cultivation of the student beginning ability, however, emphasis the student to utilize the knowledge, ability to analyze and solve problems. 


\section{Summary}

By modern innovation research and practice of engineering graphics teaching system, a series of reform, the teaching quality has been significantly improved.

1) Summarizes the traditional computer graphics, computer graphics and engineering graphics teaching reform train of thought, combining the content of configuration design and the engineering design and creative practice of combining the teaching idea, the system scheme represents the trend of the development of modern engineering graphics, better solve the traditional content of engineering drawing and modern science and technology, the basic theory teaching basic theoretical knowledge and practical ability, quality education and the organic combination of the problem.

2) The creative configuration design into teaching, lead the students to learn the enthusiasm of engineering drawings. Through computer simulation environment to help students to understand the actual production process, namely using the three dimensional CAD software modeling, process analysis and preassembly, and other functions, cooperate with multimedia courseware, make the students know the parts processing, manufacturing process, and no clear assembly structure of the composition, structure and assembly of parts of the relationship.

3) modern engineering graphics multimedia teaching system use not only solve the engineering graphics teaching model of wall facing old, aging, and advanced teaching equipment, teaching means synchronization problem of reality, such as, can make up for the deficiency of the traditional teaching, the teacher difficult to teach, students learn the content, can be easily conducted thorough three-dimensional analysis, dynamic simulated graphics performance process and the method, causes the student to quickly understand and grasp skilled. Increase the amounts of information in class, and to strengthen the students' space thinking and spatial imagination ability. Greatly improve the teaching efficiency and teaching quality.

\section{References}

[1] Virgilio Quintana, Louis Rivest, Robert Pellerin, Frédérick Venne, Fawzi Kheddouci, Will Model-based Definition replace engineering drawings throughout the product lifecycle? A global perspective from aerospace industry Computers in Industry, Vol. 61, Issue 5, pp. 497-508, June 2010.

[2] H.P. Luo, Strengthen the training of the ability of internationalization and engineering practice of Engineering Graphics Course Reform and the teaching resources construction, Journal of Huazhong Normal University(Humanities and Social Sciences), Vol. S4, pp. 216-219, 2012.10.

[3] J.Y. Zhang, H.P. Luo, T. Zhang, Y.H. Jiao, The effective integration of 3D design and engineering graphics, Journal of Engineering Graphics, No.6, pp. 151-154, 2010.

[4] X.S. Tan, R.C. Li, Y.M. Zhang, The application of three-dimensional interactive technology in development of three-view training software, Manufacturing Automation, Vol. 32, pp. 32-35, 2010.

[5] G.L.Yao, Stereoscopic thinking ability cultivation of students of engineering drawing CAD, Vocational \& Technical Education Forum, Vol. 35, pp. 65-66, 2011.

[6] Liang Yanshu, Cong Meng, Zhu Yingjie, and Guo Guimei, Consideration on Constructing and Writing for the Textbook of Engineering Graphics, Journal of Engineering Graphics, vol. 30.4, pp. 171-174, 2009.

[7] Xu Dan, Tang Yingping. Two-dimensional teaching in 3-D mechanical drawing //The 11th International Conference on Geometry and Graphics, 1-5, Guangzhou, China (9pt), 2004: 247-250.

[8] Xu Guoyu, Xue Kai, Zhao Gang. Research and practice on bilingual teaching for computer aided drawing based on network //Proceedings of the 8th China-Japan Joint Conference, Beijing Institute of Technology Press, 2007: 244-247.

[9] Xu Guoyu, Zhang Meng, Wu Yanhong. Innovative Education by Applying Digital Information Technology and Bilingualism for Engineering Graphics Curriculum, JOURNAL OF GRAPHICS, vol. 35.1, pp. 115-120, 2014. 